\title{
Older Adults' Use of Online Health Information - Do They Even Try?
}

\author{
Robert Rockmann \\ Neu-Ulm University of Applied Sciences \\ Center for Research on Service Sciences (CROSS) \\ robert.rockmann@hs-neu-ulm.de
}

\author{
Heiko Gewald \\ Neu-Ulm University of Applied Sciences \\ Center for Research on Service Sciences (CROSS) \\ heiko.gewald@hs-neu-ulm.de
}

\begin{abstract}
Online health information holds the potential to support older adults in taking active control of their health and well-being. Yet, despite generally using the Internet, many seniors do not make use of health information provided via the Internet. Understanding why older Internet users do not use online health information is consequently of high importance. Drawing on post-adoption research, a model is developed and empirically validated that examines how the interplay of health need, health knowledge, exploratory IT behavior and benefit expectations jointly accounts for seniors' online health information use. This research contributes to the literature by focusing explicitly on older adults and by providing a better understanding how health need and health knowledge enable and inhibit online health information use.
\end{abstract}

\section{Introduction}

The Internet significantly changed the 'mechanics and economics' of health information for the broad population [1] and has become a major source of health information and decision support. The Internet allows presenting health information in more accessible ways, tailored to for specific audiences and provides anonymity in sensitive topics [2]. Consumers greatly benefit from access to health information, reporting higher participation in health-related decision making, increased understanding of and adherence to their care, higher engagement in health improving behavior, as well as better relationships with their physicians [3]. Online health information is, thus, an important way to enable consumers becoming the 'source of control' in making their healthcare decisions [3]. As in 2012, about $70 \%$ of U.S. adult Internet users accessed health information online [4] and about two-thirds of all U.S. Internet users feel better informed about health than five years ago because of their Internet use [5].
Despite these proliferations, however, there is one group that -although actually using the Internetsignificantly lags behind using online health information: older adults around the age of 60 . Whilst U.S. Internet users between 18 to 64 report relatively homogenous rates around $71-76 \%$ of having looked for health information online in the last 12 months, only about $58 \%$ of the U.S. Internet users aged 65 do so [4].

Older adults are significantly at risk to suffer from chronic illnesses [6] and those with a chronic disease are, in turn, more likely to "contribute to the explosion of health care costs in the U.S." [7]. Given that the older segment is expected to grow, health expenditures for seniors are likewise expected to rise [6]. It is expected that health care systems worldwide will be confronted with older adults, who will live longer and cost more to treat [8].

Given the outlined potentials of online health information in supporting seniors to take active control of their health and well-being [9], understanding the reasons why older Internet users do not use online health information is consequently of high importance. Clearly, online health information is unlikely to have any impacts on seniors health behavior unless it is actually used [10].

Surveys on adults' online health information use [e.g., 11, 12,13] point out that seniors' online health information use is highly related to their health literacy and health condition. Thus, it may be that these two factors serve as the motivating and likewise inhibiting factors of seniors' online health information use.

However, research addressing this important issue is scarce as literature reviews at the intersection of older adults and health IT use point out $[14,15,16,17$, 18]. Most of todays' available studies are directed towards predicting seniors' intentions to use specific health-related systems, such as telehealth and remote patient monitoring systems $[19,20]$, mobile health services [21], or other specific patient systems [22, 23]. The important roles health condition and health literacy might play in seniors' health IT use have been either largely ignored [18] or remained inconclusive [22, 23]. Thus, it is important to examine the mechanisms how 
these factors promote or inhibit older adults' actual online health information use in greater detail [18].

Towards this end, research in post-adoptive IT behavior [24] indicates that individuals' enhanced IT use (i.e., using new features) is to a large extent a result of their motivation and exploration $[25,26]$. To the extend that 'Online Health Information Use' represents a form of seniors' enhanced post-adoptive Internet use, motivation and exploration behavior might be helpful in understanding how health need and health literacy translate into seniors' online health information use.

Thus, the objective of our research is to examine how the interplay of seniors' health literacy, health need, and exploratory IT behavior accounts for their actual use of online health information.

By drawing on a post-adoption perspective, we specifically examine the role of exploratory IT behavior as a mediating link between health-related factors and online health information use as a consequence. We thereby contribute to research at the intersection of older adults' health IT use by examining how motivational factors account for health IT behavior and extend research on the antecedents and consequences of exploratory IT behavior.

Our paper proceeds as follows: In the following section, we will provide background information on recent advancements in post-adoption research. Building on these insights, we then propose our research model and proceed with the development of our hypotheses. After that, we illustrate our methodological research approach and report the results from our empirical study. Subsequently, we discuss how our study contributes to research on older adults' online health information use and post-adoption research, derive practical implications, discuss our study's limitations and further research directions.

\section{Post-adoptive IT behavior}

Understanding post-adoptive behavior is gaining attraction in information systems (IS) research [e.g., 27, 28]. Post-adoptive behavior can, for instance, denote the decisions to adopt new features, as well as actual feature use and extension behaviors of an individual after an IT application has been installed and applied by the user in accomplishing her/his activities [24]. Consequently, IS research proposed different types of post-adoptive IT use -such as enhanced, extended, or innovative use [24, 27, 29, 30]in order to understand how a system's benefits and intended outcomes can be unleashed.

These use types usually refer to as using a system in a more sophisticated or novel way by making more use of the functions inherent in a system. Enhanced use, for instance, reflects "novel ways of employing IT features" [29, p. 362] and includes using a formerly unused set of available features. Similarly, extended use denotes "using more of the technology's features to support an individual's task performance" [30]. Innovative use, likewise describes the application of IT in novel ways [25].

What drives these post-adoptive use types is consequently of high importance [24, 25, 29]. Towards this end, especially users' exploratory behavior has been advocated to promote enhanced system use [24, 26]. Exploratory user behavior denotes the extent to which a user actively seeks new purposes of a given technology [26, 28, 31, 32, 33]. Hereto, Ahuja and Thatcher [28, p. 431] proposed 'Trying to Innovate with IT', defined as a 'user's goal of finding new uses of existing workplace information technologies". Trying to Innovate with IT denotes an actual behavior with goal-direction [28]. Innovative and enhanced use, as well as exploratory behavior are considered essentially as a self-driven behavior [34].

Motivational factors and mechanisms account largely for variations in exploratory behavior and enhanced use [29, 34]. Whereas much of the research on post-adoptive behavior currently takes place in organizational settings examining the influence of the organizational environment in supporting employees innovative and exploratory IT behavior [e.g., 26, 28, 35 , the roles of intrinsic and extrinsic motivations accounting for such variations have been examined in greater detail more recently. In this regard, it has been shown that perceived usefulness, a factor accounting for extrinsic motivation associated with favorable jobrelated outcomes, influences exploratory behavior [32, 33]. Various forms of intrinsic motivation can likewise account for variations in exploratory behavior [33, 35]. In this vein, $\mathrm{Li}$ et al. [25] observed that intrinsic motivation to increase knowledge as well as motivation to experience stimulation highly accounts for innovative IT behavior. In similar vein, Tennant et al. [36] observed that intrinsic motivation and domainrelated knowledge accounts for variations in IS use.

Taken these insights together, although prior research has greatly improved our understanding of factors driving system exploration, for the most part, however, these studies have taken place in organizational settings and examined the influence of organizational environment stimulating exploratory behavior. What drives exploratory behavior in private settings, however, has not been examined yet. Moreover, despite the preliminary evidence that exploratory behavior can account for enhanced system use [26], Wang et al. [37] call for further investigations of the behavioral outcomes of innovative IT behavior.

To the extend that 'Online Health Information Use' represents a form of enhanced post-adoptive use, 
motivation and exploration behavior might be helpful in understanding how health need and health literacy translate into online health information use.

\section{Research model and hypotheses}

Seniors are more threatened to suffer from diseases [7] and online health information can support seniors in their health-related decision making by obtaining knowledge about diseases, symptoms, or treatments [14] not only to cope with an acute health issue, but likewise to enhance their engagement in preventive health behavior. Although using the Internet in general, however, older adults are significantly less likely to obtain health information from the web [4]. It is, thus, important to understand the motivational mechanisms leading seniors to use online health information.

Drawing on the insights gained about post-adoptive behaviors, such as enhanced, extended, and innovative IT uses, in this research, we conceptualize 'Online Health Information Use' as a type of enhanced seniors' IT use as it reflects the notion of using more of technology's available features [26]. Precisely, 'Online Health Information Use' is here defined as the extend to which seniors obtain health-related information and support for health-related decision making with IT. To understand the variations in seniors' online health information usage, we propose our research model (Figure 1), describe our factors under consideration and develop our hypotheses next.

System exploration is the process of searching for new ways of using the system [26]. Seniors' exploratory IT behavior is hereunto referred to Trying to Innovate with IT and reflects a senior's goal of finding new uses of existing information technologies for tasks of personal importance [adapted from 28]. Trying as a behavior reflects a process of achieving an end-state, such as the attainment of goals [38, 39], or the process that "puts new ideas (i.e. new ways of using IT) into action" [37, p. 1107]. The more individuals engage in IT exploration behavior, the more new features are likely to be found and applied [26]. A recent empirical study supports the notion that exploratory behavior leads to extended system use [26]. Studies report that those older adults, who have a higher tendency towards 'openness-to-experience' are much more likely to seek health information on the Web [12]. Such 'openness', in turn, acts as an important intrinsic motivation to engage in exploratory IT behavior [35, 37]. Thus, to the extend that seniors regard online health information of personal importance, higher engagement of exploratory behavior should likely lead to seniors' enhanced Internet use by making use of the 'health information feature' the web offers. We hypothesize:

\section{H1a: Exploratory IT behavior positively affects Online Health Information Use.}

Like any other demographic group, seniors are not monolithic in their technology adoption and use [40]. Age itself is still an important differentiator, given that not only Internet adoption significantly decreases with age [40], but likewise online health information usage and these rates continue to decrease with higher ages [4]. Whereas the web has become a 'normal' way of obtaining health information for younger Internet users, for older adults using the web for health purposes may be more 'novel', different, or 'innovative'. What characterizes behavior as 'normal' or 'innovative' is "in the beholder's eyes" [25, p. 661]. Thus, it is likely that online health information use is much more a result of seniors' IT exploration attempts for seniors of higher age, constituting age as a potential moderator. We hypothesize:

H1b: 'Trying to Innovate with IT' has a higher influence for older than for younger seniors.

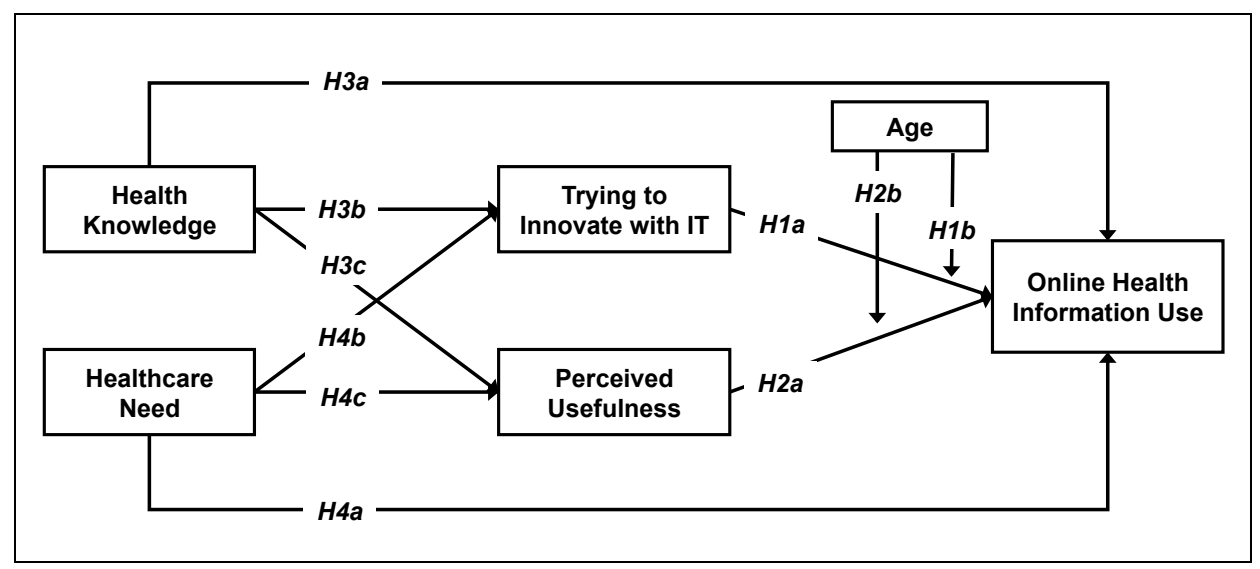

Figure 1. Research model 
Whilst exploratory IT behavior denotes the actual process of searching for new ways to use IT leading to online health information usage, seniors' must associate an actual benefit from using IT for health purposes. Expecting positive outcomes from a behavior is clearly the driving force of human behavior [e.g., 41, 42]. To this end, Perceived Usefulness (PU) reflects the extent to which an individual believes that using IT will help him or her to attain better health outcomes [43]. Plenty of research demonstrated that usefulness perceptions are not only of high importance in initial technology acceptance, but continue to predict sustained actual usage whilst other factors such as ease of use diminish [43, 44]. Enhanced use of a system is significantly determined by such positive associations [30]. Not surprisingly, positive evaluations largely affect consumers' decision to make use of health IT $[22,45]$ and their actual online health information use [10] as well. Similarly, benefit perceptions act as strongest predictor of performing health-related behavior [46]. We hypothesize:

\section{H2a: Usefulness perceptions positively affect Online Health Information Use}

However, studies indicate that the older adults are, the less likely they are to trust the Internet as health information source [47], indicating that the older adults become, the less they perceive the Internet as an adequate and, thus, useful information source.

\section{H2b: 'Perceived Usefulness' has less influence as age increases.}

Given the high importance of health literacy and health need, we next provide arguments how these two factors influence seniors' exploratory IT behavior and usefulness perceptions that are here considered as the principal factors driving online health information use.

Health Knowledge reflects "the extent of knowledge and understanding of personal health problems" [22, p. 243]. Health domain knowledge or health literacy is a major precursor of online health information use [2] and of effectively using consumer health IT [23]. Without adequate health knowledge, lay individuals are confronted with a large search space making it difficult to them separating the relevant from the irrelevant information [2], given that not all online health information is of high quality [48].

Thus, those who have higher knowledge about their health and how to care for themselves may benefit more from using online health information, as they more readily understand the information searched for and retrieved [23]. Similarly, interest in health information is one of the forces leading online users to obtain health information from the web [4]. In motivation research, individuals' intrinsic motivation to know refers to engagement in an activity for the sake of the pleasure and satisfaction arising from learning, exploring, or trying to understand new things [49]. It is related to exploration, intrinsic curiosity, as well as the intrinsic motivation to learn [50]. Recent IS research indicates that this type of intrinsic motivation greatly encourages users to engage in innovative and exploratory IT behavior [25] and accounts for variations in IT use [36]. In related IS research, it has been shown that domain-relevant knowledge enhance variations in system use [36]. Information seeking reflects a kind of learning [2] and, thus, those who have a higher baseline knowledge of health may seek to enhance their knowledge further on, leading to heightened motivation to explore new ways of finding information using computers. Based on these lines of reasoning, we hypothesize:

\section{H3(a,b,c): Health Knowledge is positively associated with (a) Online Health Information Use, (b) Trying to Innovate with IT, and (c) Perceived Usefulness}

Healthcare Need in this research reflects the frequency and diversity of physician visits and the presence of a chronic disease [22]. Individuals, and especially older adults, can greatly differ in their healthcare needs [45]. Healthcare need constitutes an important variable in the context of consumer health IT [22]. As frequently observed, adult Internet users suffering from diseases are more likely than other online adults to gather health-related information from the web [7, 51] and similarly in the case of older adults [11]. In a study examining intentions to use a patient portal, Klein [45] found that higher healthcare needs predict patients' intentions to use the system only for informational purposes, indicating that healthcare needs is a cue to obtain more information. In this vein, health behavior researchers suggest that a cue, or trigger, is the necessary condition for engagement in health-promoting behaviors $[46,52]$. Such cues can be either external or internal; whereas external cues refer to events or information from outside, such as a reminder from a dentist, internal cues can stem out of physiological states, such as pains [46]. Thus, as adult Internet users suffering from diseases tend to be more interested in online health information [53], those users might be more motivated to engage in exploratory IT behavior in the pursuit of obtaining health information to better manage their health needs. We hypothesize:
H4(a,b,c,): Healthcare Need is positively associated with (a) Online Health Information Use, (b) Trying to Innovate with IT, and (c) Perceived Usefulness 
In addition, we control for further demographic variables (i.e., gender, income, education) and for 'perceived ease of use' given that these might influence our dependent variable [e.g., 4, 11, 43, 54].

\section{Methodology}

To test our model, we conducted a quantitative field survey in the U.S. among the general population of people aged 60 and above. Our questionnaire was based on established instruments and adapted -if necessary- to our research context (see Table 1). Several pre-tests with the target group led to minor adjustments of the items to improve understanding.

Access to the target group has been frequently shown to be difficult [e.g., 55] and using an onlinesurvey might attract rather technology-savvy older adults causing potentially biased results. Therefore, we employed a convenience sampling method using a paper-and-pen based field survey approach that has been shown to be successfully for gathering data from the target group [e.g., 21]. We collected data randomly at public places such as senior citizen centers, adult schools, and pedestrian zones in the second half of 2015. In total, we received 234 surveys and removed those with respondents being younger than 60 years or due to incomplete data. The remaining 180 surveys constitute the basis of our analysis. $64 \%$ of the respondents were female, the average age was 73 years (Min: 60; Max; 101; SD: 7.4), 59\% were married, and most respondents reported an annual household income between 50k and 149k USD. The educational level is for $42 \%$ a post-graduate study, followed by $34 \%$ who graduated college.

\section{Data analysis and results}

We analyzed the data using Partial Least Squares (PLS) with the software SmartPLS 3.0 [56]. Analysis involved the common two-step procedure [57].
Thus, we first assessed the measurement model and as results in Table 2 outline, we found satisfactorily support of its quality. All latent variables have been measured with reflective items. Indicator reliability required items to be significant and loadings above 0.707 [57] resulting in dropping the chronic disease variable of health need. All other items are significant with values of at least 0.889 . All constructs' values for Cronbach's Alpha (CA) and Composite Reliability (CR) exceed the threshold of 0.70 and values for Average Variance Extracted (AVE) exceed the minimum of 0.50 [58] suggesting sufficient reliability. Discriminant validity was assessed by observing that each item loads highest on its designated construct (i.e., cross-loadings) [57] and by ensuring that the square roots of AVEs are greater than the correlation [58]. The heterotrait-monotrait ratio with highest value of 0.682 is below the threshold of 0.850 and provides further support for sufficient discriminant validity [59].

Given that we had to collect self-reported data from a single source at one point of time and place, our data might be subject to common method bias (CMB) [60]. While collecting the data, however, we ensured the participants for anonymity and that there are no 'wrong' or 'right' answers for the survey questions asked in order to mitigate threats of social-desirability biases [60]. To observe the presence of CMB in our final data, we employed two different techniques. First, Harman's single factor test indicated that only $43 \%$ of the variance accounted to one factor, which is below the threshold of $50 \%$ and, thus, gives initial support for the absence of high CMB [60]. Second, we performed a latent common method factor analysis [60, 61, 62], a frequently employed test in IS research [e.g., 26, 63]. Hereto, an additional CMB factor containing all indicators is added to the model and all indicators of the theoretical constructs are transformed into singleitem factors [62]. Then, the influence of the CMB factor on each single-item factor is compared with the influence of its theoretical construct by observing

Table 1. Measurement instrument

\begin{tabular}{|c|c|c|c|}
\hline Construct & Items & Scale & Reference \\
\hline $\begin{array}{l}\text { Online Health } \\
\text { Information Use }\end{array}$ & $\begin{array}{l}\text { 1) 'I personally use the Internet to look up information about health related topics' } \\
\text { 2) 'I use computer-technology to research healthcare providers before making a decision } \\
\text { to seek medical care' }\end{array}$ & $\begin{array}{l}\text { 7-point; } \\
\text { 'not at all - } \\
\text { very often' }\end{array}$ & Own items \\
\hline $\begin{array}{l}\text { Trying to } \\
\text { Innovate with IT }\end{array}$ & 2 items; e.g., 'I try to find new uses of computer-technology for tasks important to me.' & \multirow{4}{*}{$\begin{array}{l}\text { 7-point; } \\
\text { 'strongly } \\
\text { agree - } \\
\text { disagree' }\end{array}$} & $\begin{array}{l}\text { Adapted } \\
\text { from }[28]\end{array}$ \\
\hline $\begin{array}{l}\text { Perceived } \\
\text { Usefulness }\end{array}$ & $\begin{array}{l}3 \text { items; e.g., 'I believe using computer-technologies by my own will support critical } \\
\text { aspects of my own healthcare.' }\end{array}$ & & \multirow{2}{*}{$\begin{array}{l}\text { Adapted } \\
\text { from }[43]\end{array}$} \\
\hline $\begin{array}{l}\text { Perceived Ease of } \\
\text { Use }\end{array}$ & $\begin{array}{l}3 \text { items; e.g., 'I believe computer-technologies are easy for me to use, when using them } \\
\text { for health-related purposes.' }\end{array}$ & & \\
\hline $\begin{array}{l}\text { Health } \\
\text { Knowledge }\end{array}$ & 2 items; e.g., 'I understand my health problems and how to care for them.' & & {$[22]$} \\
\hline Health Need & $\begin{array}{l}\text { 1) Number of face-to-face physician visits in last } 6 \text { months, 2) Number of different } \\
\text { physicians visited in last } 6 \text { months, 3) Presence of a chronic disease (yes/no) }\end{array}$ & - & {$[22]$} \\
\hline
\end{tabular}


Table 2. Psychometric properties of the measurement model

\begin{tabular}{|c|l|c|c|c|c|c|c|c|c|}
\hline \multicolumn{2}{|c|}{} & \multicolumn{9}{c|}{ Discriminant Validity } \\
\hline 1 & Construct & CR & CA & AVE & 1 & 2 & 3 & \\
\hline 2 & Trying to Innovate with IT & 0.966 & 0.930 & 0.935 & 0.462 & $\mathbf{0 . 9 6 7}$ & & & \\
\hline 3 & Perceived Usefulness & 0.972 & 0.958 & 0.922 & 0.580 & 0.495 & $\mathbf{0 . 9 6 0}$ & & \\
\hline 4 & Health Knowledge & 0.918 & 0.823 & 0.849 & 0.332 & 0.303 & 0.308 & $\mathbf{0 . 9 2 2}$ & \\
\hline 5 & Health Need & 0.896 & 0.769 & 0.812 & 0.123 & 0.140 & 0.187 & -0.087 & $\mathbf{0 . 9 0 1}$ \\
\hline
\end{tabular}

changes $\mathrm{R}^{2}$ values. In our case, the CMB factor explains an average $\mathrm{R} 2$ of $0.04 \%$ compared to an average $R^{2}$ of $86.95 \%$. The ratio of $1: 2391$ indicates that the influence of the CMB factor is much smaller, suggesting that $\mathrm{CMB}$ is not of high concern.

To rule out rival explanations accounting for variations in our dependent variable, we further controlled for the influence of PEOU, gender, income, and education. As these control variables did not exert any significant effects and did not account for additional variance in the dependent variable, we excluded these from further analysis.

Next, we analyzed the results of the structural model. As depicted in Figure 2, results indicate that our research model explains $42.1 \%$ of the variance in seniors' Online Health Information Use. Out of the ten hypothesized relationships, eight found statistical support. Specifically, exploratory IT behavior (i.e., Trying to Innovate with IT) is positively related to seniors' online health information use and this relationship increases with higher age, supporting H1a and H1b. As expected, perceived usefulness likewise accounts for variations in senior's online health use, yet the hypothesized interaction effect with age is not significant. Thus, $\mathrm{H} 2 \mathrm{a}$ is supported whereas $\mathrm{H} 2 \mathrm{~b}$ is not. Health Knowledge significantly increases online health information use of older adults, their exploratory IT behavior, as well as their usefulness perceptions, supporting H3a, H3b, and H3c. Lastly, whereas healthcare need does not pose a significant relationship with online health information use, higher healthcare needs increase seniors' engagement in exploratory behavior and their usefulness perceptions, giving support for $\mathrm{H} 4 \mathrm{~b}$ and $\mathrm{H} 4 \mathrm{c}$ but not for $\mathrm{H} 4 \mathrm{a}$.

We discuss our findings' implications for theory and practice next.

\section{Discussion}

The Internet has become an important medium to provide health information to lay users in order to empower them becoming actively involved in their own healthcare and to improve their health-related knowledge and decision making $[1,2]$. As older adults are significantly more at risk to suffer from chronic illnesses and other diseases [6, 7], online health information is ideally positioned to support their wellbeing. Yet, despite being actually using the Internet, older adults frequently do not make use of health information available online [4]. Given that online health information is unlikely to have any impacts on seniors unless it is actually used [10], our research was

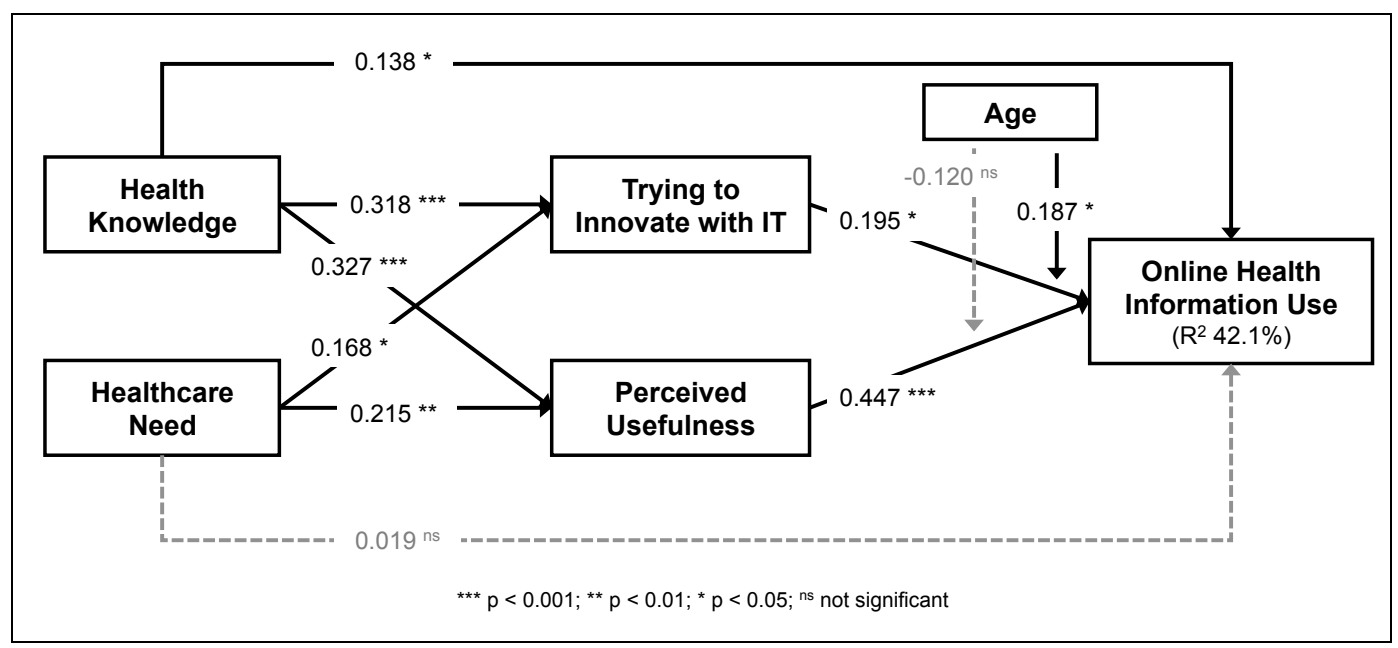

Figure 2. Results of the structural model 
consequently motivated to understand the variations in seniors' online health information use. We discuss our contributions for theory and practical implications as well our study's limitations in this final section.

\subsection{Theoretical contributions}

As introductorily outlined, research on older adults' health IT behavior is scarce $[14,15,16,17,18]$ and is either descriptive in nature [e.g., 11, 12, 13] or targeted at predicting intentions to use specific health-related systems [19, 20, 21, 22, 23]. This study, thus, makes the following important contributions to research.

First, our research contributes to literature by focusing explicitly on older adults in order to grasp a better understanding of their online health information use behavior, a target group that received scant attention in theory-guided research.

Second, although studies indicate their importance, the role of health literacy and healthcare needs in health IT use have not been examined in great detail yet [18] leading to inconclusive results [22, 23]. By drawing on recent advancements in IS research, we employed a post-adoptive perspective focusing on the notion of enhanced IT use [26, 28, 29]. This allowed us to place exploratory IT behavior as the mediating link of health need and health literacy towards online health information usage and -as our data reflect-found solid empirical support this approach. Thus, health needs provide the cue or trigger to seek for new uses of IT that leads to higher online health information use. In addition, those with higher health needs are much more likely to perceive IT as useful in supporting their health. In similar vein, health literacy, or health knowledge, serves as the necessary domain knowledge that stimulates individual's motivation to find new IT uses leading to higher use of online health information. This, in turn, indicates that individual's inadequate health knowledge acts as a strong inhibitor. Taken these findings together, our study therefore extends prior research reporting mixed results [22, 23] and responds to calls to investigate the role of health status in health IT acceptance and use [14].

Third, our study contributes to research on postadoptive IT behavior. Exploratory use behaviors received comparatively less attention in IS research [35] and has taken largely place in organizational settings [26, 28, 29, 35]. To this end, our study is among the first that successfully examined the applicability of these concepts in a private setting. Our research further extends prior research about the antecedents and consequences of individuals' innovative IT uses [35]. Precisely, we found individual's needs (i.e., healthcare needs) and domainrelevant knowledge (i.e., health knowledge) as novel antecedents of exploratory IT behavior in private settings. We thereby complement previous research in identifying factors that motivate individuals' innovative IT behavior [28, 35]. Moreover, our study complements recent advancements about the consequences of innovative IT behavior [26], as that our study demonstrated that exploratory IT behavior leads to specific types of enhanced use (i.e., online health information use). Given our observed interaction with age, we further have shown that exploratory IT behavior does not equally predict enhanced use for all users. In sum, our study responds to the urge to gain a better understanding about the factors and mechanisms that promote post-adoptive behavior [24, 25, 29].

\subsection{Practical implications}

We can derive important practical implications from our findings. In order to attract seniors towards online health information usage, the usefulness must be clearly communicated. Thereby, it must be taken into account, that seniors perceive health IT less useful and are less likely to engage in online health information seeking, when they do not possess adequate health knowledge. Thus, online health information must be designed and written for lay users without high health literacy. In parallel, seniors have to be better informed about health knowledge in order to motivate them to engage in online use. Basic training interventions to course the web for health information have been shown to be highly successful for older adults [64]. Moreover, seniors perceive health IT as more useful, when they have higher health needs. Given that online health information should be useful for preventive behaviors as well, communicating the benefits to those without severe health issues and needs must be focused. In this vein, media should not only communicate about the potentials of health IT for seniors but should likewise encourage them to explore for new uses of their technology they use. Motivating seniors to 'try out' new features of the Internet may be likewise achieved through persuasion of people important to them, such as their children, grandchildren or other relatives. Given the absence of the influence of perceived easeof-use as a control variable, communicating that online health information does not demand much efforts might be further supportive for seniors' perception about the usefulness of health IT and to encourage their exploratory IT behavior.

\subsection{Limitations and further research}

Despite the contributions and implications derived from our study, however, one has to take the 
limitations of our research into account when interpreting the results.

From a methodological perspective, a weakness lies in the cross-sectional research design, where data has been collected at the same point at time [26, 60]. Moreover, we employed self-assessed measures that are subjective in nature and might not represent objective health knowledge, health need, or usage. We measured usage in terms of frequency, which is not without its criticism as individuals often tend to overand underestimate their behavior [27]. Concerning our data collection approach, we surveyed seniors at public places and institutions and, thus, we may have missed those, who are less outgoing or have severe physiological issues forcing them to stay at home.

From a theoretical perspective, our research has the following limitations. We conceptualized exploratory IT behavior (i.e., Trying to Innovate with IT) on a general level. Prior research has shown that usefulness perceptions towards IT influences trying behavior [28], yet because of our general conceptualization of trying, we could not model and examine this relationship. Thus, further research could incorporate the goaldirection of 'improving health' to examine this relationship. Moreover, given our focus on individuals' health factors, we neglected other variables that might account for health information usage. In this respect, further research could examine the influence of individual IT-related factors, such as computer selfefficacy, computer anxiety, or Personal Innovativeness in IT, which have been found to be important factors of older adults' IT behavior [26, 35, 65, 66]. Organizational research revolving around exploratory IT behavior has shown that environmental factors can stimulate employees' attempts to find novel purposes for the target system. In this respect, further research could examine which factors in non-organizational settings have equal influence. Lastly, we conceptualized 'online health information' very broadly and did not distinguish between different types of health information, such as general health information (e.g., wellness, vitamins) and medical information (e.g., treatment, symptoms,). Thus, further research is required to explain different types of health information seeking [67].

\section{Acknowledgment}

This research received funding from the German Federal Ministry of Education and Research (BMBF) under grant code 01FR14021. The responsibility for the content of this publication lies with the authors.

\section{References}

[1] Keselman, A., R. Logan, C.A. Smith, G. Leroy, and Q. Zeng-Treitler, "Developing informatics tools and strategies for consumer-centered health communication", Journal of the American Medical Informatics Association, 15(4), 2008, pp. 473-483.

[2] Keselman, A., A.C. Browne, and D.R. Kaufman, "Consumer health information seeking as hypothesis testing", Journal of the American Medical Informatics Association, 15(4), 2008, pp. 484-495.

[3] Prey, J.E., J. Woollen, L. Wilcox, A.D. Sackeim, G. Hripcsak, S. Bakken, S. Restaino, S. Feiner, and D.K. Vawdrey, "Patient engagement in the inpatient setting: a systematic review", Journal of the American Medical Informatics Association, 21(4), 2014, pp. 742-750.

[4] Fox, S., and M. Duggan, "Health Online 2013", 2013, http://www.pewinternet.org/files/old-

media//Files/Reports/PIP_HealthOnline.pdf, accessed June, 3rd 2016

[5] Pew Research Center, "Americans Feel Better Informed Thanks to the Internet", 2014, http://www.pewinternet.org/files/2014/12/PI_InformedWeb_ 120814_02.pdf, accessed June, 3rd 2016.

[6] Campbell, R.J., "Meeting seniors' information needs: Using computer technology", Home Health Care Management \& Practice, 20(4), 2008.

[7] Pew Research Center, "The Diagnosis Difference", 2013, http://www.pewinternet.org/files/old-

media//Files/Reports/2013/PewResearch_DiagnosisDifferenc e.pdf, accessed June, 3rd 2016.

[8] Chatterjee, S., and A. Price, "Healthy living with persuasive technologies: framework, issues, and challenges", Journal of the American Medical Informatics Association, 16(2), 2009, pp. 171-178.

[9] Eysenbach, G., "What is e-health?", Journal of Medical Internet Research, 3(2), 2001, pp. 1-2.

[10] Liang, H., and Y. Xue, "Online Health Information Use by Disabled People: The Moderating Role of Disability", in: Proceedings of the 34th International Conference on Information Systems, 2013

[11] Choi, N., "Relationship between health service use and health information technology use among older adults: analysis of the US National Health Interview Survey", Journal of Medical Internet Research, 13(2), 2011, p e33.

[12] Flynn, K.E., M.A. Smith, and J. Freese, "When do older adults turn to the internet for health information? Findings from the Wisconsin Longitudinal Study", Journal of General Internal Medicine, 21(12), 2006, pp. 1295-1301.

[13] Morrell, R.W., C.B. Mayhorn, and J. Bennett, "A Survey of World Wide Web Use in Middle-Aged and Older Adults", Human Factors, 42(2), 2000, pp. 175-182. 
[14] Or, C.K., and B.-T. Karsh, "A Systematic Review of Patient Acceptance of Consumer Health Information Technology", Journal of the American Medical Informatics Association, 16(4), 2009, pp. 550-560.

[15] Wagner, N., K. Hassanein, and M. Head, "Computer use by older adults: A multi-disciplinary review", Computers in Human Behavior, 26(5), 2010, pp. 870-882.

[16] Li, Y.-C., "Review of Empirical Research in Recent Decade About the Use of IT for Older Adults", in: Human Aspects of IT for the Aged Population. Design for Aging, Springer, 2015, pp. 221-229.

[17] Ma, Q., K. Chen, A.H.S. Chan, and P.-L. Teh, "Acceptance of ICTs by Older Adults: A Review of Recent Studies", in: Human Aspects of IT for the Aged Population. Design for Aging, Springer, 2015, pp. 239-249.

[18] Marton, C., and C.W. Choo, "A review of theoretical models of health information seeking on the web", Journal of Documentation, 68(3), 2012, pp. 330-352.

[19] Demiris, G., H. Thompson, J. Boquet, T. Le, S. Chaudhuri, and J. Chung, "Older adults' acceptance of a community-based telehealth wellness system", Informatics for Health and Social Care, 38(1), 2013, pp. 27-36.

[20] Giger, J.T., N.D. Pope, H.B. Vogt, C. Gutierrez, L.A Newland, J. Lemke, and M.J. Lawler, "Remote patient monitoring acceptance trends among older adults residing in a frontier state", Computers in Human Behavior, 44(2015, pp. 174-182.

[21] Guo, X., Y. Sun, N. Wang, Z. Peng, and Z. Yan, "The dark side of elderly acceptance of preventive mobile health services in China", Electronic Markets, 23(1), 2013, pp. 4961 .

[22] Wilson, E.V., and N.K. Lankton, "Modeling patients' acceptance of provider-delivered e-health", Journal of the American Medical Informatics Association, 11(4), 2004, pp. 241-248.

[23] Or, C.K., B.-T. Karsh, D.J. Severtson, L.J. Burke, R.L. Brown, and P.F. Brennan, "Factors affecting home care patients' acceptance of a web-based interactive selfmanagement technology", Journal of the American Medical Informatics Association, 18(1), 2011, pp. 51-59.

[24] Jasperson, J.S., P.E. Carter, and R.W. Zmud, "A Comprehensive Conceputalization of the Post-Adoptive Behaviors Associated with IT-Enabled Work Systems", MIS Quarterly, 29(3), 2005, pp. 525-557.

[25] Li, X., J.P.-A. Hsieh, and A. Rai, "Motivational Differences Across Post-Acceptance Information System Usage Behaviors: An Investigation in the Business Intelligence Systems Context", Information Systems Research, 24(3), 2013, pp. 659-682.

[26] Liang, H., Z. Peng, Y. Xue, X. Guo, and N. Wang, "Employees' Exploration of Complex Systems: An Integrative View", Journal of Management Information Systems, 32(1), 2015, pp. 322-357.
[27] Burton-Jones, A., and D.W.J. Straub, "Reconceptualizing system usage: An approach and empirical test", Information Systems Research, 17(3), 2006, pp. 228-246.

[28] Ahuja, M.K., and J.B. Thatcher, "Moving beyond intentions and toward the theory of trying: effects of work environment and gender on post-adoption information technology use", MIS Quarterly, 29(3), 2005, pp. 427-459.

[29] Bagayogo, F.F., L. Lapointe, and G. Bassellier, "Enhanced use of IT: A new perspective on post-adoption", Journal of the Association for Information Systems, 15(7), 2014, pp. 361-387.

[30] Hsieh, J.P.-A., and W. Wang, "Explaining employees' extended use of complex information systems", European Journal of Information Systems, 16(3), 2007, pp. 216-227.

[31] Nambisan, S., R. Agarwal, and M. Tanniru, "Organizational Mechanisms for Enhancing User Innovation in Information Technology", MIS Quarterly, 23(3), 1999, pp. 365-395.

[32] Karahanna, E., and R. Agarwal, "When the Spirit is Willing: Symbolic Adoption and Technology Exploration", University of Georgia, Athens, 2006

[33] Li, X., and J. Hsieh, "Impact of Transformational Leadership on System Exploration in the Mandatory Organizational Context", in: Proceedings of the 28th International Conference on Information Systems, 2007

[34] Li, X., J. Hsieh, and A. Rai, "A motivational account for post-acceptance routine and innovative use: Introducing the concept of tri-dimensional intrinsic motivation", in: Proceedings of the International Conference on Information Systems, 2009

[35] Magni, M., L. Maruping, L. Caporarello, and S. Basaglia, "Innovating with technology in team contexts: a trait activation theory perspective", in: Proceedings of the International Conference on Information Systems, Year

[36] Tennant, V., A. Mills, and W. Chin, "A Generalized Darwinism Perspective on Changes in Individuals' Use of Information Systems", in: Proceedings of the 35th International Conference on Information Systems, 2014

[37] Wang, W., X. Li, and J.P.-A. Hsieh, "The contingent effect of personal IT innovativeness and IT self-efficacy on innovative use of complex IT", Behaviour \& Information Technology, 32(11), 2013, pp. 1105-1124.

[38] Mathur, A., "Examining Trying as a Mediator and Control as a Moderator of Intention-Behavior Relationship", Psychology \& Marketing, 15(3), 1998, pp. 241-259.

[39] Bagozzi, R.P., and P.R. Warshaw, "Trying to consume", Journal of Consumer Research, 17(2), 1990, pp. 127-140.

[40] Pew Research Center, "Older Adults and Technology Use", 2014 http://www.pewinternet.org/files/2014/04/PIP_Seniors-andTech-Use_040314.pdf, accessed June, 3rd 2016. 
[41] Fishbein, M., and I. Ajzen, Belief, Attitude, Intention, and Behavior: An Introduction to Theory and Research, Addison-Wesley, Reading, MA, 1975.

[42] Bandura, A., Self-Efficacy: The Exercise of Control, Freeman, New York, 1997.

[43] Venkatesh, V., M.G. Morris, G.B. Davis, and F.D. Davis, "User Acceptance of Information Technology: Toward a Unified View", MIS Quarterly, 27(3), 2003, pp. 425-478.

[44] Venkatesh, V., and F.D. Davis, "A Theoretical Extension of the Technology Acceptance Model: Four Longitudinal Field Studies", Management Science, 46(2), 2000, pp. 186-204.

[45] Klein, R., "An empirical examination of patientphysician portal acceptance", European Journal of Information Systems, 16(6), 2007, pp. 751-760.

[46] Carpenter, C.J., "A meta-analysis of the effectiveness of health belief model variables in predicting behavior", Health Communication, 25(8), 2010, pp. 661-669.

[47] Hesse, B.W., D.E. Nelson, G.L. Kreps, R.T. Croyle, N.K. Arora, B.K. Rimer, and K. Viswanath, "Trust and Sources of Health Information", Archives of Internal Medicine, 165(22), 2005, pp. 2618-2624.

[48] Kitchens, B., C.A. Harle, and S. Li, "Quality of healthrelated online search results", Decision Support Systems, 57(2014, pp. 454-462.

[49] Vallerand, R.J., "Toward a Hierarchical Model of Intrinsic and Extrinsic Motivation", Advances in Experimental Social Psychology, 29(1997, pp. 271-360.

[50] Vallerand, R.J., and R. Blssonnette, "Intrinsic, Extrinsic, and Amotivational Styles as Predictors of Behavior: A Prospective Study", Journal of Personality, 60(3), 1992, pp. 599-620.

[51] Fox, S., and K. Purcell, "Chronic Disease and the Internet", 2010, http://www.pewinternet.org/files/oldmedia//Files/Reports/2010/PIP_Chronic_Disease_with_topli ne.pdf, accessed June, 3rd $201 \overline{6}$.

[52] Janz, N.K., and M.H. Becker, "The Health Belief Model: A Decade Later", Health Education \& Behavior, 11(1), 1984, pp. 1-47.

[53] Fox, S., "The Social Life of Health Information, 2011", 2011, http://www.pewinternet.org/2011/05/12/the-social-lifeof-health-information-2011/, accessed June, 3rd 2016.

[54] Davis, F.D., R.P. Bagozzi, and P.R. Warshaw, "User Acceptance of Computer Technology: A Comparison of Two Theoretical Models", Management Science, 35(8), 1989, pp. 982-1003.
[55] Heart, T., and E. Kalderon, "Older adults: are they ready to adopt health-related ICT?", International Journal of Medical Informatics, 82(11), 2013, pp. e209-e231.

[56] Ringle, C.M., S. Wende, and J.-M. Becker, "SmartPLS 3", SmartPLS GmbH, Boenningstedt, 2015

[57] Chin, W.W., "The partial least squares approach to structural equation modeling", Modern methods for business research, 295(2), 1998, pp. 295-336.

[58] Fornell, C., and D.F. Larcker, "Evaluating structural equation models with unobservable variables and measurement error", Journal of Marketing Research, 1981, pp. 39-50.

[59] Henseler, J., C.M. Ringle, and M. Sarstedt, "A new criterion for assessing discriminant validity in variance-based structural equation modeling", Journal of the Academy of Marketing Science, 43(1), 2015, pp. 115-135.

[60] Podsakoff, P.M., S.B. Mackenzie, J.-Y. Lee, and N.P. Podsakoff, "Common Method Biases in Behavioral Research: A Critical Review of the Literature and Recommended Remedies", Journal of Applied Psychology, 88(5), 2003, p 879.

[61] Liang, H., N. Saraf, Q. Hu, and Y. Xue, "Assimilation of Enterprise Systems: The Effect of Institutional Pressures and the Mediating Role of Top Management", MIS Quarterly, 31(1), 2007, pp. 59-87.

[62] Williams, L.J., J.R. Edwards, and R.J. Vandenberg, "Recent advances in causal modeling methods for organizational and management research", Journal of Management, 29(6), 2003, pp. 903-936.

[63] Maier, C., S. Laumer, C. Weinert, and T. Weitzel, "The effects of technostress and switching stress on discontinued use of social networking services: a study of Facebook use", Information Systems Journal, 25(3), 2015, pp. 275-308.

[64] Chu, A., J. Huber, B. Mastel-Smith, and S. Cesario, "Partnering with Seniors for Better Health: computer use and Internet health information retrieval among older adults in a low socioeconomic community", Journal of the Medical Library Association, 97(1), 2009, pp. 12-20.

[65] Niehaves, B., and R. Plattfaut, "Internet adoption by the elderly: employing IS technology acceptance theories for understanding the age-related digital divide", European Journal of Information Systems, 23(6), 2014, pp. 708-726.

[66] Maier, C., "Personality within Information Systems Research: A Literature Analysis", in: Proceedings of the 28th European Conference on Information Systems, 2012

[67] Weaver, J.B., D. Mays, G. Lindner, D. Eroğlu, F. Fridinger, and J.M. Bernhardt, "Profiling characteristics of internet medical information users", Journal of the American Medical Informatics Association, 16(5), 2009, pp. 714-722. 